\title{
Yolk sac count matters
}

\author{
Ashok K. Todani ${ }^{1 *}$, Kiralata Todani ${ }^{2}$ \\ ${ }^{1}$ Department of Obstetrical Sonoghraphy, ${ }^{2}$ Department of Obstetrics and Gynecology, Sonography Clinic and \\ Laparoscopy Centre, Raniganj, West Bengal, India
}

Received: 04 November 2019

Accepted: 03 December 2019

\section{*Correspondence:}

Dr Ashok K. Todani,

E-mail: ashoktodani@gmail.com

Copyright: $\odot$ the author(s), publisher and licensee Medip Academy. This is an open-access article distributed under the terms of the Creative Commons Attribution Non-Commercial License, which permits unrestricted non-commercial use, distribution, and reproduction in any medium, provided the original work is properly cited.

\begin{abstract}
Yolk sac is the first anatomical structure identified within the gestational sac at 5+ weeks and is diagnostic of intrauterine pregnancy. It is attached through the yolk stalk with the intestinal cavity of the embryo and is supplied with blood vessels that transport nutritive yolk products to the developing embryo. It provides nutritive, metabolic, endocrine, immunological and haemopoietic functions. The poor quality and early regression of a yolk sac in presence of embryonic heart beats are more specific than the large size of a yolk sac in predicting pregnancy loss. Number of yolk sac is usually indicative of amnionicity, except in select reported cases of monoamniotic twins when two yolk sacs are present. Singleton pregnancies contain only one yolk sac as a rule. We have come across a case of elderly non-diabetic primi gravida where presence of one extra yolk sac has accelerated growth of single foetus by 8 days in early first trimester. We followed it up to 16 weeks of gestation when both yolk sacs disappeared. It was concluded that two yolk sacs conferred extra mileage of growth to the foetus due to doubled yolk sac functions, and this extra growth persisted throughout.
\end{abstract}

Keywords: Embryonic heartbeat, Gestation sac, Haemopoietic, Monoamniotic, Pseudosac, Trimester

\section{INTRODUCTION}

Functionally, yolk sac is the initial source of exchange between the mother and the embryo. It provides nutritive, metabolic, endocrine, immunological and haemopoietic functions to the early developing embryo. It is the first anatomical structure identified within the gestation sac.

Demonstration of yolk sac confirms that the sac represents an early intra-uterine pregnancy, as opposed to a pseudo sac appearance with an ectopic pregnancy. ${ }^{1}$ The yolk sac diameter increases steadily at the rate of $0.1 \mathrm{~mm}$ per day until 10 weeks of gestational age to a maximum of 5 to $6 \mathrm{~mm}^{2}$

Yolk sac also serves as anatomical landmark to locate the embryonic disc and detect early cardiac activity. This is important in early embryonic blood supply, and much of it is incorporated into the primordial gut during the fourth week of development. The calcified yolk sac remnant, which is located between the amnion and the chorion, may be seen at sonography on the foetal surface of the placenta.

Different variations of yolk sac in number, size and quality including vascularity need attention. Monitor yolk sac in early pregnancy especially with history of early pregnancy loss or repeated early pregnancy loss.

Discrepancy of yolk sac numbers has been paid attention to only in cases of different twin pregnancies, but not in singleton pregnancy. We have assessed impact of 2 yolk sacs in live singleton pregnancy in both first trimester and early second trimester). 


\section{CASE REPORT}

Mrs. R. B., 30 years, primi gravida, married for one year, had her LMP on $15^{\text {th }}$ May 2019.

Her urine for pregnancy was negative on 18.06 .2019 , but positive on $20^{\text {th }}$ June 2019.

Her ultrasound examination revealed as follows:

1. On $5^{\text {th }}$ July.19: At 7 weeks and 2 days GA, CRL was $19.5 \mathrm{~mm}=8$ weeks 3 days; MSD $=33 \mathrm{~mm}=9$ weeks; 2 distinct yolk sacs were seen; so net gain of 8 days growth (Figure 1).

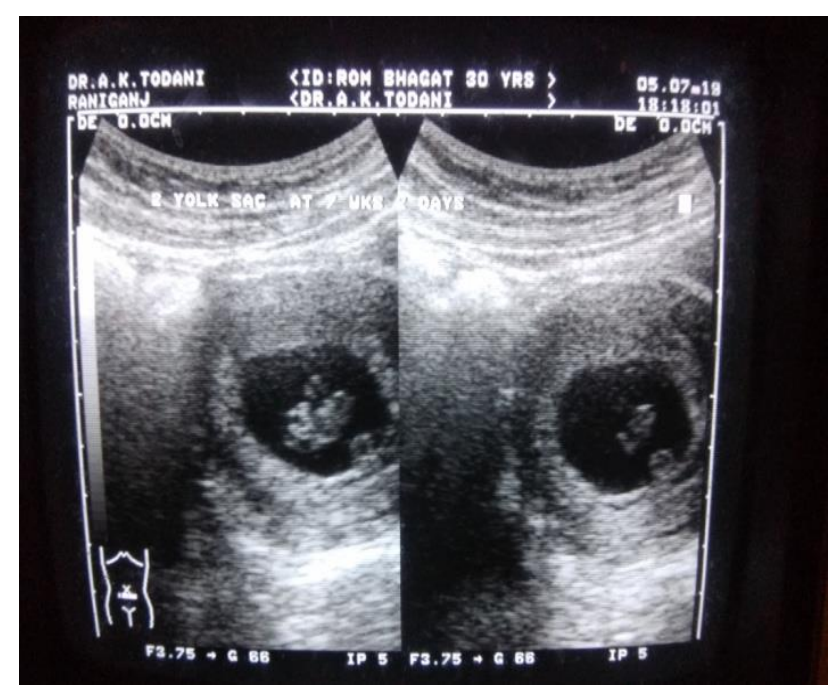

Figure 1: Scan at 7 weeks and 2 days; growth gain of 8 days.

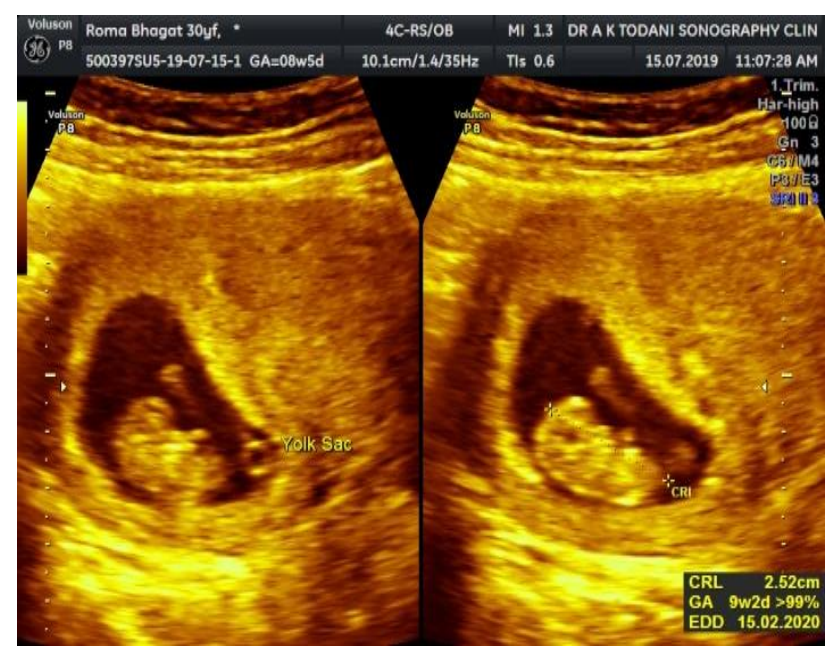

Figure 2: Scan at 8 weeks and 5 days.

2. On $15^{\text {th }}$ July 2019: At 8 weeks 5 days GA, CRL was $25.2 \mathrm{~mm}=9$ weeks 2 days; one yolk sac was normal but second one started shrinking; net gain of 4 days growth (Figure 2).
3. On $26^{\text {th }}$ July: At 10 weeks and 2 days GA, CRL $=$ $45.7 \mathrm{~mm}=11$ weeks and 2 days; One yolk sac measured $4.3 \mathrm{~mm}$ and normal but second atrophied to $1.8 \mathrm{~mm}$; excellent cardiac activity; net gain of 7 days growth (Figure 3).

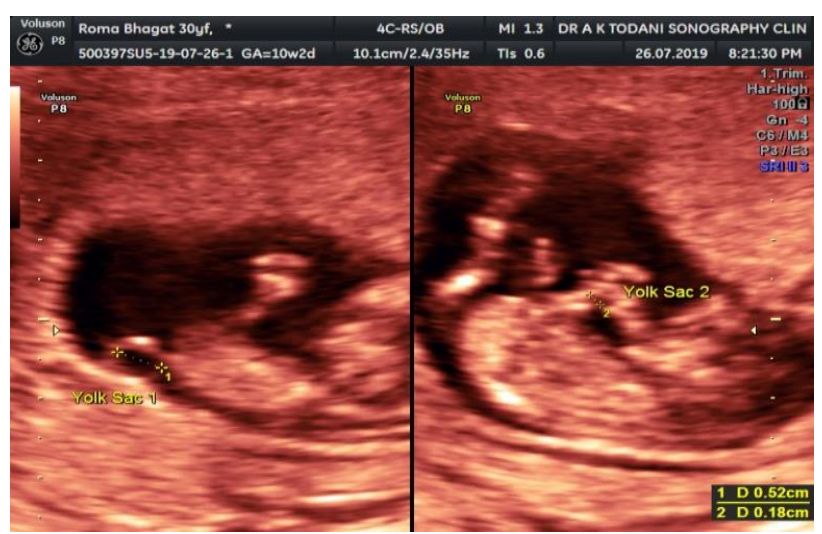

Figure 3: Scan at 10 weeks and 2 days; both yolk sacs persisting.

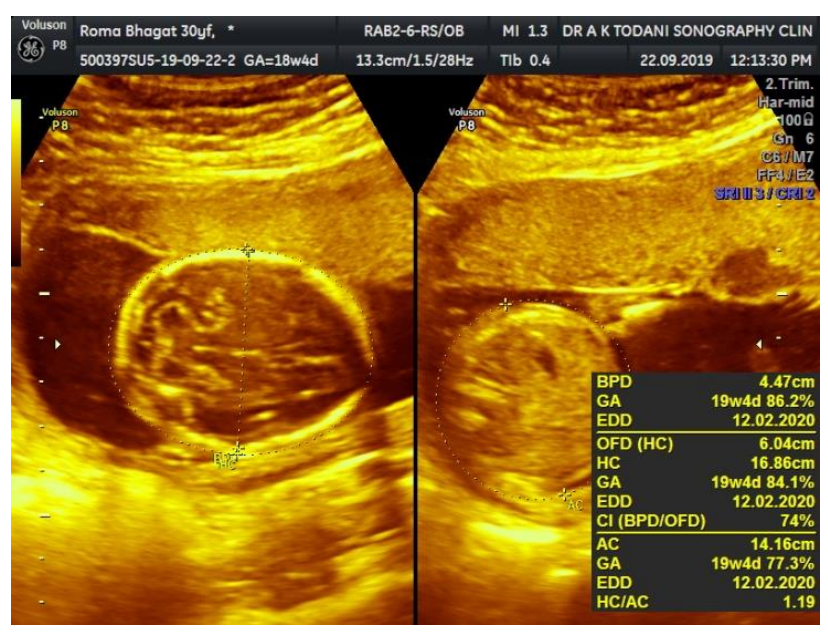

Figure 4: Scan at 18 weeks and 4 days; nett growth gain of one week.

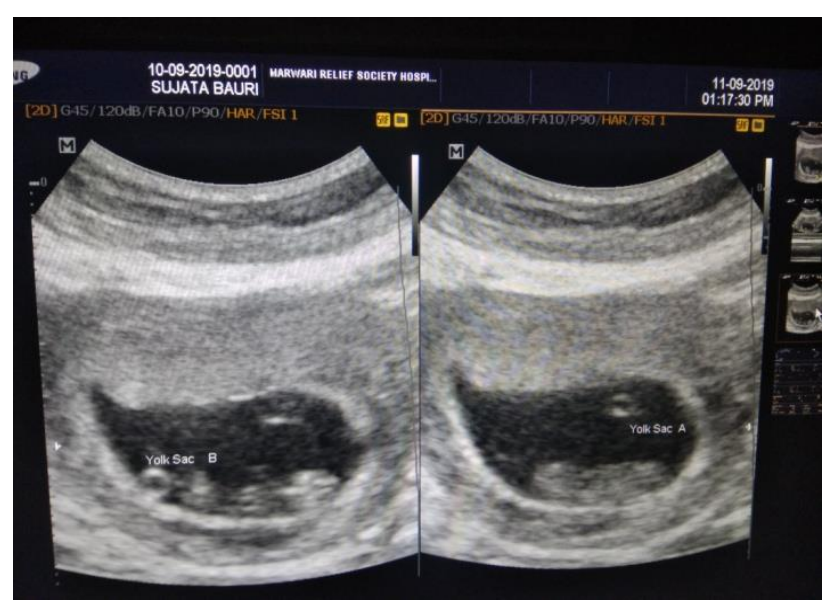

Figure 5: Monoamniotic twins with 2 yolk sacs at 7 weeks. 
4. On 22 $2^{\text {th }}$ September 2019: At 18 weeks and 4 days GA, BPD and FM were 19 weeks and 4 days. Both yolk sacs not located or disappeared: net gain of 7 days which persisted for 11 weeks' time of follow-up (Figure 4).

\section{Differential diagnosis for double yolk sacs}

Physiological hernia, yolk sac tumours, piled up Wharton's jelly in umbilical cord;

Double marker screening at 10 weeks was within safety region. 4D anomaly scan at 19 weeks and 4 days depicted normal scan without any defect. Accelerated growth of foetus was apparent in first trimester.

We also report a case of monoamniotic twins, scanned on $11^{\text {th }}$ September 2019, having 2 yolk sacs at 7 weeks (Figure 5).

\section{Outcomes}

Yolk sac is very sensitive organelle in first trimester leading to and responsible for ultimate pregnancy outcome. Additional yolk sac definitely affects foetal growth in first trimester. One small yolk sac depletes nutritional status of foetus making prognosis grave, good additional yolk sac appears to be of benefit so. In this case of double yolk sac, extra growth of 8 days was clinched in a span of two weeks; or the foetus grew by 22 days in 14 days.

\section{DISCUSSION}

Following changes assessed by 2D ultrasound are related to spontaneous abortion prediction:

1. Absence of yolk sac

2. Too large - more than $6 \mathrm{~mm}$ yolk sac (over 2SD, sensitivity $16 \%$, specificity $97 \%$, Positive predictive value or PPV - 60\%).

3. Abnormal pattern of yolk sac vascularity is related to decreased vitelline blood flow, which may cause progressive accumulation of nutritive secretions not utilised by embryo. This process ends by enlargement of yolk sac indicative of early pregnancy failure. ${ }^{3}$

4. Yolk sac abnormalities are consequences than the cause of altered embryonic development. Too small less than $3 \mathrm{~mm}$ (below 2SD, sensitivity $15 \%$, specificity $95 \%$, PPV-44\%) - In one analysis of a group of patients between $8^{\text {th }}$ and $12^{\text {th }}$ weeks of gestational age, it was found that patients with a yolk sac diameter less than $2 \mathrm{~mm}$ were associated with an adverse outcome. ${ }^{4}$ Lack of nutritive secretions due to inefficient vascularization of yolk sac was the root cause.

5. Irregular shape: mainly wrinkled with indented walls. Storage of nutrients is hampered due to wall resistance obstructing transport.
6. Degenerative changes- abundant calcifications with decreased translucency of the yolk sac: Yolk sac calcification results from the typical dystrophic changes that occur in non-viable cellular material. Absent blood flow signals suggest longstanding foetal demise. ${ }^{5}$

7. Number of yolk sacs: should be equal to number of the embryos. But discrepancy is seen.

- In a series of 11 cases of MA twins, 7 had single yolk sacs and 4 had double yolk sacs. ${ }^{6}$

- In another study, two yolk sacs were present in upto a third of all MCMA twin pregnancies, dispelling the original concept that a single yolk sac is diagnostic of MCMA pregnancies. The 2 yolk sacs in monoamniotic twins were associated with higher numbers of male fetuses; there were no other differences between one and two yolk sacs for maternal and foetal outcome. ${ }^{7}$ There were no other significant differences between one and two yolk sacs for maternal or foetal outcome.

- Yolk sac number doesn't predict reliable amnionicity in monochorionic twin pregnancies. They reported a case of monochorionic monoamniotic twin pregnancy with two distinct yolk sacs in early first trimester ultrasound. ${ }^{8}$

8. Diabetic embryopathy: Maternal diabetes induces yolk sac injuries by damaging the morphology of cells and altering the dynamics of organelle by damaging yolk sac vasculature leading to impairment of nutrient transportation due to vasculopathy and ultimate birth defects. ${ }^{9}$

Limitations of this study was very small sample size as the condition is extremely rare and not reported anywhere yet.

\section{CONCLUSION}

Yolk sac differentiation occurs shortly before that of amnion. But in this case of singleton pregnancy, presence of additional yolk sac pushed the growth of foetus by additional one week which persisted in long term. Nutritive function of yolk sac appears to pump in extra nutrition to promote excessive growth.

Yolk sac health or number cannot be assessed clinically, it is only an embryological event coupled with sono scan landmark. Any agent or mechanism has not yet been identified so far which can affect or influence number or structure or function of yolk sac. Lot of research work is needed to invent or identify agents or drugs which can alter 'state' of yolk sac when administered externally thereby opening a new vistas or horizon of therapy. Prognosis of many early pregnancies can thus be altered. Yolk sac vasculopathy appears to be the probable mechanism for birth defects.

Overall, yolk sac number can't be used to assign amnionicity in monoamniotic twins. 


\section{ACKNOWLEDGMENTS}

Author would like to thank Dr. Rishi Todani who worked tirelessly for this paper.

Funding: No funding sources Conflict of interest: None declared

Ethical approval: Not required

\section{REFERENCES}

1. Stampone C, Stampone C, Nicotra M, Muttinelli C, Cosmi EV. Transvaginal sonography of the yolk sac in normal and abnormal pregnancy. Jour Clin Ultrasound. 1996;24:3-9.

2. Jauniaux E, Jurkovic D, Henriet $\mathrm{Y}$, Rodesch F, Hustin J. Development of the secondary human yolk sac: correlation of sonographic and anatomical features. Hum Reprod. 1991;6:1160-6.

3. Kurjak A, Kupesic S, Parallel doppler assessment of yolk sac and intervillous circulation in normal pregnancy and missed abortion. Placenta. 1998:19:619-23.

4. Green JJ, Hobbins JC. Abdominal ultrasound examination of the first trimester foetus. yolk sac theory in diabetic embryopathy: Molecular mechanism and link to structural birth defects. Am J Gynecol. 1988;159:165-75.
5. Harris RD, Vincent LM, Askin FB. Yolk sac calcification: a demise in the first trimester. Radiol. 1988:166:109-16.

6. Park SY, Chung JH, Kim MY. Prediction of amnionicity using the number of yolk sacs in monochorionic multifetal pregnancy. J Korean Med Sci. 2017;32(12):2016-20.

7. Fenton C, Reidy K, Demyaneko M, Palma- Dias R, Cole S, Umsted MP. All from Royal Women's hospital, Victoria, Australia. Foetal Diagn Ther. 2019:46(3):193-9.

8. Corbett SL, Shmorgun D. Yolk sac number does not predict reliably amnionicity in monochorionic twin pregnancies: a case of a monochorionic monoamniotic twin pregnancy with two distinct yolk sacs on early first-trimester ultrasound. Ultrasound Obstet Gynecol. 2012;39: 607-8.

9. Dong D, Raece EA, Lin X, WuY, Arias Villele N, Yang P. Yolk sac theory in diabetic embryopathy: Molecular mechanism and link to structural birth defects. Am J Obstet Gynecol. 2016;214:192-202.

Cite this article as: Todani AK, Todani K. Yolk sac count matters. Int J Reprod Contracept Obstet Gynecol 2020;9:444-7. 